\title{
O BOOM INFORMACIONAL: A TECNOLOGIA E A GÊNESE DA CIÊNCIA DA INFORMAÇÃO
}

\section{THE INFORMATION BOOM: THE TECHNOLOGY AND THE GENESIS OF INFORMATION SCIENCE}

\author{
Edcleyton Bruno Fernandes da Silva ${ }^{1}$ \\ biblioebfs@yahoo.com.br \\ Diogo Araújo Sampaioº \\ diogosampaio7@hotmail.com
}

Resumo: $O$ presente artigo tem como proposta abordar o aspecto e o contexto histórico e epistemológico acerca do processo de origem e formação da Ciência da Informação $(\mathrm{Cl})$, tendo como principal fundamento o desenvolvimento da tecnologia no desenvolvimento da sociedade. A explosão informacional e o direcionamento de pesquisa que sucedeu a Segunda Guerra Mundial tiveram grande importância no desenvolver da Cl. Na discussão abordada por Saracevic, tratando da discussão por meio de autores como Shannon, Frohmann e Bush, observamos a importância dos aparatos tecnológicos para o desenvolvimento da $\mathrm{Cl}$, não deixando de mencionar o caráter a cerca da formação interdisciplinar por meio da influência de outras disciplinas (Documentação, Biblioteconomia, Arquivologia, entre outras) nos estudos do fenômeno informação, destacando que a tecnologia amplia esse fenômeno, mas que o conjunto de disciplinas retratam sua influência nas relações culturais, sociais, políticas, econômicas e tecnológicas da sociedade. Nessa perspectiva, pretende-se discutir sobre esses aspectos a gênese da Ciência da Informação. Novos olhares sobre essa ciência ganharam importância, notadamente no contexto do desenvolvimento científico e tecnológico, onde a tecnologia ganha mais uma vez

\footnotetext{
${ }^{1}$ Graduação em Biblioteconomia - UFPB. Mestre em Ciência da Informação - UFPB. Pesquisador pela UFPB. Lattes: http://lattes.cnpq.br/3726961457442749

${ }^{2}$ Graduação em Ciências Econômica - UFPB. Especialização em Gestão Pública Universitária - UFPB. Mestre em Economia - UFPB. Economista da UFPB. Lattes: http://lattes.cnpq.br/9148799196369122
} 


\section{Bibliocanto@}

destaque na propulsão do desenvolvimento da ciência que estuda a informação. A discussão das correntes teóricas de uma área de estudo colabora para sua formação enquanto campo científico e, concomitantemente, predomina os espaços da ciência e tecnologia com a capacidade de desenvolver uma sociedade. Para isso, entender tais contextos se configura na reflexão das teorias que compõem uma área do conhecimento.

Palavras-chave: Ciência da Informação. Origem. Informação e Tecnologia.

\section{INTRODUÇÃO}

A informação constitui um elemento importante não somente por estar no cotidiano das pessoas, mas por se tornar insumo para práticas públicas e sociais com um enfoque nos indivíduos, além disso, favorecer atividades que têm a informação como núcleo de estudos (FROHMANN, 1995).

O interesse na utilização de novas ferramentas para tratamento da informação despertou nos pesquisadores a preocupação em aprimorar os "artefatos" no intuito de melhorar e ampliar a disseminação das informações diante de suas necessidades. A revolução que por muitos é considerada industrial, tecnológica e científica tem-se caracterizado como impulso para o surgimento da Ciência da Informação $(\mathrm{Cl})$.

Tem circulado diversos entendimentos acerca da origem da $\mathrm{Cl}$ e sobre o contexto em que a mesma desenvolveu suas estruturas dentro do rol das ciências. A industrialização, o desenvolvimento e a pós-modernidade têm-se mantido como parâmetros para a construção de uma ciência que trata da informação que, até então, não recebia o menor tratamento e a devida importância.

Considerada, por muitos, como uma ciência nova: moderna, pós-moderna e contemporânea, a $\mathrm{Cl}$, dentro do seu campo teórico, discute sobre sua origem constantemente devido a sua importância e ao papel que desempenha na 


\section{- Bibliocanto@}

sociedade. No entanto, para superar tais questões embrionárias e emergir dentro de um processo de construção de raízes, faz-se necessário abandonar algumas estruturas que não conseguem desenvolver-se e precisam ser descartadas dentro do processo de evolução do conhecimento.

Para Bachelard (1996, p. 20), "o progresso científico efetua suas etapas mais marcantes quando abandona os fatores filosóficos de unificação fácil, tais como a unidade de ação do Criador, a unidade de organização da Natureza, a unidade lógica". Nesse sentido, uma das características da ciência e do conhecimento científico se torna o constante questionamento da sua estrutura e organização considerada pelo o autor a capacidade de "sair da contemplação do mesmo para buscar o outro" (BACHELARD, 1996, p. 21). Assim, o pensamento de Bachelard fazse incidir em nós: saber para melhor questionar.

É fato que, dentro do seu processo de desenvolvimento, a $\mathrm{Cl}$ tem agregado significativas contribuições da tecnologia da informação que trouxe novas formas de tratamento e disseminação da informação nas últimas décadas.

Este artigo tem como objetivo discutir a origem da $\mathrm{Cl}$ com base em seu surgimento no período pós-guerra, paralelamente, observando o artigo de Bush (2011) As we may think, que destaca a preocupação com uma "explosão informacional" que, através do crescimento da tecnologia, expande o processamento principalmente documental, ou seja, é por meio da necessidade de aprimorar tais procedimentos com o uso de novas tecnologias que o tratamento de uma gama muito grande de informações é aprimorado.

Bush (2011, p. 02) destaca que:

Existe hoje um volume inesgotável de pesquisas. Mas é cada vez mais evidente que enquanto a especialização ganha terreno, estamos ficando absolutamente saturados. O pesquisador é assolado pelas descobertas e conclusões de milhares de colegas conclusões que ele não consegue encontrar tempo para apreender, menos ainda para se lembrar. Entretanto, a especialização torna-se cada vez mais necessária ao progresso, e o esforço para estabelecer pontes entre as disciplinas é proporcionalmente superficial. 


\section{Bibliocanto@}

Nesse sentido, pode-se debater o surgimento da $\mathrm{Cl}$ com o aporte de desenvolvimento da tecnologia, isto é, destacando a importância desta no sentido de direcionar a área, bem como através da conjugação/colaboração de outras disciplinas (Documentação, Biblioteconomia, Arquivística, Comunicação, entre outras) consideradas próximas a $\mathrm{Cl}$, dando a ela o caráter interdisciplinar em sua formação e condição existencial fundamentada entre esses fatores. Justifica-se pela permanente discussão e pelo aprimoramento de ideias a cerca do surgimento da $\mathrm{Cl}$.

Compreender o processo de formação da Ciência da Informação consiste numa tarefa epistemológica importante tanto para seu crescimento do ponto de vista teórico, quanto da sua consolidação enquanto campo do conhecimento.

\section{DISCUTINDO A CIÊNCIA DA INFORMAÇÃO}

A discussão do desenvolvimento da Ciência da Informação tem diversos caminhos, Rayward (1997) apresenta como raiz a Documentação, Shera (1980) a trata pelo viés da Biblioteconomia e Saracévic (1996) aborda-a pela visão tecnológica. Nessa visão, tendo em vista o caminho traçado pela Ciência da Informação a partir do período pós-Segunda Guerra Mundial.

A Cl, uma ciência que segundo Saracévic (1996) caracteriza-se como interdisciplinar por natureza, oriunda da revolução científica e técnica no período que sucedeu a Segunda Guerra mundial, emerge como um campo interdisciplinar por estabelecer relações entre alguns campos do conhecimento, entre eles, Silva e Ribeiro (2002) destacam algumas disciplinas: a Biblioteconomia, a Arquivística, a Museologia, a Comunicação, a Documentação, no bojo das Ciências Sociais, a Psicologia, a Linguística, a História, a Epistemologia, a Filosofia, a Lógica, a Estatística, a Matemática e a Informática (SILVA; RIBEIRO, 2002).

Ainda na perspectiva da participação de outras áreas do conhecimento, no processo de formação da $\mathrm{Cl}$, conforme Mendonça (2014, p. 04) 
Podemos concluir que a base de conhecimento que deve nortear a teorização da ciência da informação teve origem nessa revolução tecnológica de entrelaçamento da Física com a Matemática e, definitivamente, podemos afirmar que a origem da ciência da informação nada tem a ver com a Biblioteconomia, exceto pelo fato de no Brasil terem colocado a Biblioteconomia, a Museologia e a Arquivologia sob seu guarda-chuva.

Saracévic (1996) ao apresentar as características gerais da Ciência da Informação, além de afirmar que a mesma é interdisciplinar, faz um destaque para a tecnologia, ao afirmar que $\mathrm{Cl}$ está "inexoravelmente ligada à tecnologia da informação", levando a uma mudança da sociedade moderna para uma sociedade da informação. O autor destaca que a $\mathrm{Cl}$ em conjunto com outras disciplinas possui um importante papel nessa mudança de sociedade.

Dentro das ações de informação que permeia o campo

\begin{abstract}
A ciência da informação tem utilizado, desde sua origem, algumas dessas estratégias objetivantes e objetivadoras do conhecimento, apresentando-se ora como ciência empírico-analítica, ora como meta-ciência, ainda que nos últimos anos tenha explorado, achamos que com maiores perspectivas, um pluralismo metodológico próprio das ciências sociais e de um campo interdisciplinar (GONZÁLEZ DE GOMÉZ, 2001, p. 13).
\end{abstract}

Sua característica interdisciplinar é situada de acordo com Souza (2015) pela complexidade do objeto e pela formação plural de pesquisadores. Uma ciência interdisciplinar é uma ciência ousada na busca, na pesquisa, na tentativa de transformar a insegurança num exercício do pensar, sobretudo na construção do seu estatuto epistemológico, a partir da utilização recíproca de teorias e metodologias. Então,

A interdisciplinaridade na Ciência da Informação também é evidenciada a partir de seu objeto de estudo, e sua organização discursiva se dá basicamente em dois espaços complementares, quais sejam, o reconhecimento da complexidade do objeto informação e a dificuldade de o campo definir seu objeto particular.

BiblioCanto, Natal, v. 3, n.2, p. 3 - 16, 2017. 


\section{Bibliocantoo}

No que se refere ao primeiro domínio, os arranjos discursivos têm por fundamento o entendimento amplo de que a informação se encontra circunscrita em todas as áreas de conhecimento, ou, mais amplamente, nos diversos setores da sociedade (SOUZA, 2015, p. 157).

O nascedouro do ensino interdisciplinar foi a proposição de novos objetos, de novos métodos, de uma nova pedagogia, cuja tônica primeira é a supressão do monólogo e a instauração de uma prática dialógica.

No entanto, segundo Fazenda (2007) para seu crescimento se faz necessário eliminar alguns obstáculos, são eles:

(i) Obstáculos epistemológicos e institucionais;

lii) Obstáculos psicossociológicos e culturais;

(iii) Obstáculos metodológicos;

(iv) Obstáculos quanto à formação;

(v) Obstáculos materiais.

Ao mesmo tempo em que surge essa relação disciplinar, a tecnologia vem surgindo e moldando os processos de comunicação e mediação da informação, colaborando com processo de desenvolvimento da $\mathrm{Cl}$ referente à necessidade de aprimoramento de técnicas de gestão da informação, no momento em que essa é uma das essenciais características inerentes às disciplinas que têm, dentro do seu objeto, a organização, o gerenciamento, a disponibilização, a recuperação, o acesso e o uso da informação.

Vale ressaltar que, no período de crise e de transformações pós-guerra, a $\mathrm{Cl}$ ganha destaque com o aumento do número de produção científica e com a importância sobre seu tratamento e disseminação das informações. Então, a tecnologia da informação ganha espaço como "divisor de águas" por participar desse momento em que a informação obtém status de controle e poder na sociedade.

Segundo Barreto (2002, p. 18), 


\section{Bibliocanto@}

As mudanças na tecnologia da informação, ocorridas durante os últimos anos, reorganizaram todas as atividades associadas à ciência da informação. A sociedade sempre foi mais afetada pelas transformações, ou pela natureza da tecnologia do que pelo seu conteúdo, pelo menos a curto prazo. Aqueles que convivem mais de perto com essas alterações enfrentam com maior carga as consequências sociais e físicas de uma enorme ansiedade tecnológica.

Dentro dos processos que envolvem a ascensão da Cl, Kunh (1998) destaca a estrutura paradigmática da Ciência da Informação, apontada por através da revolução científica que brota de uma "Ciência Normal" a um estado de transformação/revolução que, a partir de um momento de "crise", envolvido pelo processo de cognição, consegue evoluir e formar um novo estado do conhecimento científico.

$\mathrm{Na}$ tentativa de construir o processo de consolidação da $\mathrm{Cl}$ e o seu desenvolvimento como campo do conhecimento científico, houve um movimento categórico, técnico e científico agravando os parâmetros institucionais, buscando elucidar requisitos existenciais bem como as transformações e a ampliação do caráter investigativo a cerca da sua estruturação e composição.

Nessa concepção de espaço, Bourdieu (1983) destaca a relação que se estabelece na busca de espaço e, paralelamente, a discussão sobre as vertentes teóricas que se estabelecem dentro do regime de informação no processo de institucionalização.

Ao mesmo tempo em que Silva e Ribeiro (2002) enfatizam a importância da Documentação, Biblioteconomia e Arquivologia e outras disciplinas dentro do processo de construção da Ciência da Informação, Mendonça (2014) conclui que o norte teórico fundamental da construção da $\mathrm{Cl}$ como área do conhecimento caracteriza-se pela revolução tecnológica aglomerada às relações entre a Física e a Matemática.

A base de conhecimento que deve nortear a teorização da ciência da informação teve origem nessa revolução tecnológica de 


\section{- Bibliocantoo}

entrelaçamento da Física com a Matemática e, definitivamente, podemos afirmar que a origem da ciência da informação nada tem a ver com a Biblioteconomia, exceto pelo fato de no Brasil terem colocado a Biblioteconomia, a Museologia e a Arquivologia sob seu guarda-chuva. Perguntamos por que, se sua origem é tecnológica? Ela não acolhe estas disciplinas, apenas o fator tecnológico as relaciona. Veremos isto mais à frente. Cada uma dessas três disciplinas tem sua base de sustentação teórica própria e estabelecida, seu objeto nomeado e compreendido. Elas se enquadram nas características de ciência normal de Kuhn (1990), são conhecimentos tradicionais, dado que passaram pela crise na segunda metade do século $X X$, fato que não ocorreu com a ciência da informação, pois foi gerada neste período (MENDONÇA, 2014, p. 02).

Para a autora, há um elemento entre as disciplinas que é a informação, mas que, no entanto, esse termo se torna genérico, assim como explica a teoria de Shannon como fenômeno do século XX.

Pinheiro e Loureiro (1995) destacam o trabalha de Shannon como um dos que contribuíram fortemente para o conceito de informação, apesar dos estudos do autor estar relacionado à comunicação na perspectiva de solução de problemas de transmissão de sinais.

Shannon é um dos pesquisadores que trabalharam com Bush. Ao mesmo tempo em que Bush (2011) é tratado como um dos precursores a abordar a origem $\mathrm{Cl}$, em seu texto, ele destaca a necessidade de se criar pontes entre as disciplinas dada a grande massa informacional que era criada.

Santos (2002) apresenta o trabalho de Bush (2011) destacando a informação e o paradigma holográfico do autor. Para Santos (2002), mais importante do que a própria explosão informacional seria a interconexão de experiências e pesquisas. Para isso, com ajuda da tecnologia, seriam processados infinitos volumes de informação.

Nessa mesma concepção, Ribeiro (2008, p. 50), ao estudar o artigo de Bush, afirma que é "bastante claro que o problema do excesso de informação com que devemos lidar não é o modo de publicação, mas os limites de recepção do leitor". 


\title{
- Bibliocantoo
}

Desse modo, a importância estaria relacionada aos processos de busca e seleção da informação mais do que à própria disponibilidade oferecida pelos aparatos tecnológicos.

Santos (2002), a partir da visão de paradigmas de Kuhn, diz que a $\mathrm{Cl}$ necessita enfrentar uma nova forma de complexidade e de interatividade presentes no mundo, para isso, deve ter uma quebra com o paradigma vigente.

A discussão acerca da tecnologia na $\mathrm{Cl}$ deve ser mais ampla, pelo fato dela ter causado muitos impactos nas relações sociais e institucionais existentes. Nesse sentido, Frohmann (1995), ao estudar o caráter social, material e público da informação aponta os aparatos tecnológicos como de grande importância nessa perspectiva, tendo em vista as mudanças referentes à coleta, ao processamento e a utilização da informação causando profundas transformações na natureza e no contexto estrutural em que aquela informação consegue modificar dentro de uma estrutura social.

Dentro do escopo em que a tecnologia tem participação no processo de construção da Cl, Mendonça (2014, p. 06, grifo do autor) diz que

\begin{abstract}
Sendo filha da era tecnológica e digital não cabe a ciência da informação ter como definição todos estes parâmetros. Acreditamos que pela questão tecnológica e pela sua relação com a hermenêutica e a cibernética, apenas deve ser atribuído à $\mathrm{Cl}$ o aspecto tecnológico da informação. Estes parâmetros são característicos de um sistema e não de uma ciência. A ciência da informação não é um sistema. Nestas condições, podemos considerar a ciência da informação como: a) filha da guerra, b) nascida indiretamente da revolução de Shannon em 1948, c) resultado da explosão da informação pósArpanet.
\end{abstract}

Frohmann (1995) destaca a importância da materialidade em seu texto e aborda o tema, destacando que os enunciados possuem uma estabilidade que gera poder e força para eles. Ao relacionar com a materialidade da informação, o autor destaca que se abre um fértil campo de investigação por meio dos recursos teóricos. 


\section{Q Bibliocantoo}

Para o autor, tanto a produção quanto o processamento dos documentos digitais ocorrem fora da consciência. Frohmman (1995, p. 13) destaca ainda que:

As investigações de como informação digital é materializada por meio de sua imersão em tecnologias de processamento de informação eletrônica levam diretamente às características públicas, sociais, políticas, econômicas e culturais da informação - o que tem sido reconhecido como central para o estudo da informação.

Nesse sentido, um dos destaques do discurso de Frohmann (1995, p. 11) é o documento digital que "desafia o cenário tradicional da disseminação da informação, [...] porque a intencionalidade, característica essencial do cenário tradicional, está ausente na geração de um vasto conjunto de enunciados digitais".

A tecnologia modifica o status quo na medida em que amplia o raio de ação da informação, atingindo, assim, as formas de uso que implicam em mudanças no caráter social, material e público da informação.

\section{CONSIDERAÇÕES FINAIS}

Ao discutir o surgimento da $\mathrm{Cl}$, tendo como foco a tecnologia, observa-se que os aparatos tecnológicos modificam o cenário informacional vigente, levando, assim, às mudanças ocorridas no pós-guerra.

A explosão informacional gerou a necessidade de um maior formato para coletar, processar e utilizar a informação. Assim, a discussão que se coloca não é uma relação pura e simples do uso da tecnologia, mas de como ela modifica o contexto. Como destacado por Frohmann (1995), a tecnologia interfere nas "características públicas, sociais, políticas, econômicas e culturais da informação".

O caráter social e cultural da informação traz consigo uma perspectiva de ligação ou pontes entre disciplinas que se alimentam da tecnologia para utilizar seus recursos e consegue aproximar, ou, até mesmo, estabelecer relações, sempre 


\section{- Bibliocantoo}

modificando as estruturas de informação, seja através do desenvolvimento da ciência, cultura e tecnologia.

Vimos que a $\mathrm{Cl}$ teve suas origens atrelada às diversas áreas do conhecimento e essas tiveram notável participação tanto no seu processo de formação quando em seu desenvolvimento. Por se tratar de áreas do conhecimento que têm a informação como fator em comum de tratamento, várias são as possibilidades de relações tanto na ampliação e estruturação da disciplina como na produção do conhecimento.

Essa relação é evidenciada dentro das formas de produção científica e pode ser estabelecida através da autoria colaborativa na produção científica, em que há participação efetiva de autores com diversas formações na produção do conhecimento científico na $\mathrm{Cl}$.

Esse espaço de encontro de disciplinas tem como objeto de estudo a informação ligada diretamente ao desenvolvimento da cultura, ciência e tecnologia como suporte fundamental e diferencial da $\mathrm{Cl}$, bem como à interdisciplinaridade, ou à relação entre as disciplinas que rodeiam essa ciência que cresce a cada dia.

Desse modo, ressalta-se que o caráter interdisciplinar da $\mathrm{Cl}$ e sua formação estão relacionados tanto às disciplinas, como Documentação, Biblioteconomia e Arquivologia, como a outras relacionadas às ciências sociais. Isso retrata que a informação está concatenada aos diversos aspectos das relações sociais, públicas, econômicas e culturais.

Compreende-se a notória participação de disciplinas como a Biblioteconomia, a Documentação, a Museologia, as Ciências Sociais e as demais citadas anteriormente, pois essas áreas do conhecimento ampliaram as formas de coletar, processar e utilizar a informação através do crescimento e desenvolvimento das tecnologias da informação que propiciaram novas formas de aprimorar o tratamento da informação pelas disciplinas.

No entanto, sem o aporte tecnológico não haveria a difusão da informação por parte das disciplinas e concomitantemente o processo de crescimento e 


\section{Bibliocantoo}

desenvolvimento da $\mathrm{Cl}$ estaria a desejar quanto as suas condições de formação e difusão como área do conhecimento.

Dessa forma, podemos compreender que tanto a $\mathrm{Cl}$ quanto outras áreas do conhecimento não teriam se desenvolvido sem as contribuições da tecnologia que a aprimoraram, bem como quebraram diversos obstáculos no tratamento da informação.

Abstract: The purpose of this article is to analyze the historical and epistemological aspects of the process of origin and formation of Information Science $(\mathrm{Cl})$. Its main basis is the development of technology in the development of society. The informational explosion and the direction of research that followed World War II were of great importance in the development of IC. The discussion discussed by Saracevic, dealing with the discussion through authors such as Shannon, Frohmann and Bush, we observed the importance of the technological apparatuses for the development of IC, not forgetting to mention the character about the interdisciplinary formation through the influence of other disciplines (Documentation, Librarianship, Archivology, among others) in the studies of the phenomenon information, noting that technology amplifies this phenomenon, but that the set of disciplines portray its influence in the cultural, social, political, economic and technological relations of society. From this perspective, it is intended to discuss about these aspects the genesis of Information Science. New views on this science have gained importance, especially in the context of scientific and technological development, where technology once again stands out in the propulsion of the development of science that studies information. The discussion of the theoretical currents of an area of study contributes to its formation as a scientific field and, at the same time, dominates the spaces of science and technology with the capacity to develop a society. For this, to understand such contexts is configured in the reflection of the theories that compose an area of knowledge. 


\section{(2) Bibliocantos}

Keywords: Information Science. Origin. Information and Technology.

\section{REFERÊNCIAS}

BACHELARD, G. A formação do espírito científico: contribuição para uma psicanálise do conhecimento. Rio de Janeiro: Contraponto, 1996.

BARRETO, A. A. A condição da informação. São Paulo em Perspectiva, São Paulo, v. 16, n. 3, p. 67-74, 2002. Disponível em:

$<$ http://www.scielo.br/scielo.php?pid=S0102$88392002000300010 \&$ script=sci_arttext>. Acesso em: 20 abr. 2017.

BOURDIEU, P. O campo científico. In: ORTIZ, R. (Org.). Pierre Bourdieu: Sociologia. São Paulo: Ática, 1983. Cap.2, p. 122-155.

BUSH, V. As we may think, 1945. Tradução de Luana Villac. Revista Latina Americana de Psicopatologia Fundamental, São Paulo, v.14, n.1. mar. 2011. Disponível em: <http://dx.doi.org/10.1590/S1415-47142011000100002> Acesso em : 16 fev. 2017.

FAZENDA, I. C. A. Interdisciplinaridade: História, Teoria e Pesquisa. CampinasSP: Papirus Editora, 2007.

FROHMANN, B. Taking information policy beyond information science: applying the actor network theory. In: ANNUAL CONFERENCE OF THE CANADIAN ASSOCIATION FOR INFORMATION SCIENCE / ASSOCIATION CANADIENNE DES SCIENCES DE L'INFORMATION, 23., 1995. Edmonton. Electronic Proceedings... $14 \mathrm{f}$. Disponivel em:

<http://www.fims.uwo.ca/people/faculty/frohmann/actor.htm >. Acesso em: 20 jan. 2017.

GONZÀLES DE GÓMEZ, M. N. Para uma reflexão epistemológica acerca da Ciência da Informação. Perspectivas em Ciência da Informação, Belo Horizonte, v. 6, n. 1, p. 5-18, jan./jun. 2001. Disponível em:

<http://portaldeperiodicos.eci.ufmg.br/index.php/pci/article/view/433/243>. Acesso em: 22 dez. 2016.

MENDONÇA, E. Epistemologia, Tecnologia, Paradigma: as origens da Ciência da Informação. Datagramazero, Rio de Janeiro, v. 15, 2014. Disponível em: $<$ https://datagramazero.wordpress.com/2014/12/13/epistemologia-tecnologiaparadigma-as-origens-da-ciencia-da-informacao/>. Acesso em: 20 jan. 2017. 


\section{Bibliocanto}

PINHEIRO, L. V. R.; LOUREIRO, J. M. M. Traçados e Limites da Ciência da Informação. Ciência da Informação, Brasília, v. 24, n.1, p. 42-53, 1995. Disponível em: <http://revista.ibict.br/ciinf/article/view/609>. Acesso em: 05 jan. 2017.

RAYWARD, W. B. The origins of Information Science and the International Institute of Bibliography/International Federation for Information and Documentation (FID). Journal of the American Society for Information Science, New York, v. 48, n. 4, p. 289-300, apr. 1997. Disponível em: $<$ http://people.lis.illinois.edu/ wrayward/OriginsoflnfoScience.pdf>. Acesso em: 11 fev. 2017.

RIBEIRO, A. E. Hipertexto e Vannevar Bush: um exame de paternidade. Informação \& Sociedade. Estudos, João Pessoa, v. 18, p. 45-58, 2008. Disponível em: <http://www.ies.ufpb.br/ojs/index.php/ies/article/view/1811/2271>. Acesso em: 15 mar. 2017.

SANTOS, N. B. dos. Informação e Paradigma Holográfico: A Utopia de Vannevar Bush. Datagramazero, v. 3, n.6, p. 01-21, 2002. Disponível em: <http://www.dgz.org.br/dez02/Art_06.htm>. Acesso em: 18 jul. 2016.

SARACEVIC, T. Ciência da Informação: origens, evolução e relações. Perspectivas em Ciência da Informação, Belo Horizonte, v. 1, n. 1, p. 41-62, jan./jun. 1996. Disponível em:

<http://portaldeperiodicos.eci.ufmg.br/index.php/pci/article/view/235/22>. Acesso em: 27 jan. 2017.

SHERA, J. Sobre Biblioteconomia, Documentação e Ciência da Informação. In: GOMES, H. E. (org.). Ciência da Informação ou Informática? Rio de Janeiro: Calunga, 1980. p. 91-105.

SILVA, A. M.; RIBEIRO, F. Das "Ciências" documentais a Ciência da Informação: ensaio epistemológico para um novo modelo curricular. Porto: Afrontamento, 2002.

SOUZA, E. D. A Ciência da Informação: fundamentos epistêmico-discursivos do campo científico e do objeto de estudo. Maceió: Edufal, 2015. 